\title{
Public Infrastructure Project Tendering Through Public Private Partnerships (PPP) - A Literature Review
}

\author{
Shamsida Saidan Khaderi ${ }^{1}$, Ani Saifuza Abd Shukor ${ }^{1}$, Anis Sazira Bakri $^{1}$ and Rohana Mahbub ${ }^{1}$ \\ ${ }^{1}$ Center of Studies for Quantity Surveying, Faculty of Architecture, Planning and Surveying, University Teknologi \\ MARA, Shah Alam, Selangor.
}

\begin{abstract}
Public Private Partnerships (PPP) in Malaysia have been inundated by various controversies and criticisms from the very beginning. Many of the constraints that occur in PPP projects is due to the failure in tendering stage. Bidding or tender for a PPP project is usually much more complex than a traditional publicsector project involving the appointment of top advisers and designers at a great fee in the preparation of detailed design, comprehensive planning, extensive bid documentation, and lengthy clarifications. These problems as being the reason behind several high-profile withdrawals during the early PPP tenders, resulting in some preferred bidders being selected by defaults as other competitors withdrew. Base on the above premise, this study attempts to propose PPP tendering process improvement in Malaysian construction industry. This paper aims at providing an overview about literature on tendering process in PPP/PFI. The objectives of the research are to identify and understand the PPP implementation practices in Malaysia; to determine issues and challenges in PPP tendering stage; and to propose PPP tendering improvement. The approach is based on the analysis of the pertinent publications on the theme. Three main interest areas can be found in the literature which is; tendering procedure, issues and challenges, and strategies that could be enhance PPP tendering process in the Malaysian construction industry.
\end{abstract}

\section{Introduction}

In the past couple of decades, the Public-Private Partnership model (PPP) has been used by governments around the world to facilitate investments in public infrastructure. A PPP is a way of delivering and funding public infrastructure projects where project risks shared between the public and private sector. In a PPP there is a long-term agreement between the government and a private partner where the service delivery objectives of the government aligned with the profit objectives of the private partner [18]. Besides, the government requires the quality and quantity of the service it necessitates from the private partner. The private partner may be tasked with the design, construction, financing, operation, and management of the infrastructure asset and the delivery of a service to the government or the public using that asset. According to Anders \& Schutze [2], public infrastructure projects can be divided into three main categories: Transport infrastructure, for example, tunnels, bridges, ports, roads, and rail systems.; Utilities, for example, power generation, waste management, water, and telecommunications.; Social and service infrastructure, which can be further divided into standard assets, for example, administrative buildings and custom-built assets, for example, schools, universities, hospitals, and major cultural institutions.
Malaysian government planned to widen the implementation of PPP-based projects during the 10th Malaysia Plan period to increase the opportunities for the private sector to participate in the infrastructure and utility development. This measure will also help to drive growth in the construction industry, which has been contracting over the last nine years. PPP has just been introduced in Malaysia, but in the United Kingdom (UK), it has been practiced for nearly 20 years. The PPP concept was introduced in the UK in 1995 and has been used as a mechanism to procure public services from administrative entities, and to exploit the expertise of the private sector in the areas of financing, design, construction, and operation during providing public services [21]

The PPP vehicle varies from privatization, in which the private sector is liable for providing services. Preferably, this vehicle fundamentally includes a structure in which the government purchases services such as the construction and operation of public facilities from the private sector and provides administrative services for public use [35]. In current years, there has been an increasing market of PPP/PFI for the improvement and procedure of infrastructure projects in Malaysia. However, a few empirical studies have been conducted in its overall implementation and tendering process. Some PPP projects are the subject of lengthy political debate before they go to bid, causing further delay in their execution [38]. The London Underground

\footnotetext{
*Corresponding author: shamsida72@yahoo.com
} 
PFI project, where struggle emerged between the London Lord Mayor and the central government, is an example [4]

A political debate may also extend beyond the project tender. In New South Wales, Australia, planning, and decision-making for a motorway project dragged on for nearly one and a half decades. Despite many projects procured to date, the effectiveness of PPP is still subjected to considerable debate. A few investigations proposed that PPP has delivered benefits over conventional public sector procurement [39]. For instance, a survey of PPP projects by the National Audit Office revealed that only $22 \%$ of projects experienced an increase in construction costs after the contract had been awarded [33]. According to Shamsida [23], Abdul Rahman et al. [39] and Syuhaida [34], many of the constraints occur in PPP projects in Malaysia are due to the failure in the tendering process. It is essential that an open competitive tender process is adapted to select the most qualified contractor based on their expertise and experience.

This problem also arises in other countries like the UK and Australia. Studies conducted by [21],[35],[40],[11],[5],[23] have shown that the most critical stage in the implementation of PPP projects is at the tendering stage. Among the reasons identified are the lengthy negotiation period for a decision and the high cost involved in the process and the tender price. Therefore, this paper aims to determine the issues and constraints that arise as well as improvements that should be incorporated into the process of tendering for PPP projects in Malaysia. A very high cost of the bidding process does not only represent a waste of resources that could be invested in buildings and services but becomes a barrier to enter the PFI market for all but a small number of significant players. It has led to a reduction of competition in the sector, with many specialists, niche, and innovative organizations now turning away from PFI projects, unable to bear the oftenenormous cost of bidding for contracts. Besides, as bids have become ever more complex, the time required to undertake the bidding process is now excessively lengthy, with subsequent delays to project delivery.

\section{Methods}

This article extensively reviews the normative literature to provide a comprehensive understanding of PPP tendering process in public infrastructure projects. The paper consolidates the current debate on the meaning and relevant issues regarding tendering in PPP/PFI. The findings of other researchers regarding the PPP bidding procedure, problems and challenges in PPP/PFI tendering process were compared. The article then purified different viewpoints concerning the relative importance of PPP bidding process in public infrastructure projects and lastly, due to the complexity of such, it is essential to provide strategies to enhance the PPP/PFI process.

\section{Procedures for PPP Tendering}

PPP/PFI is a type of collaboration between the public and private sector whereby a stand-alone business made, funded and managed by the private sector as a package that encompasses construction management, maintenance, and repair works as well as replacement of public amenities comprising buildings, infrastructure, equipment, and facilities. The methods used for the implementation of PPP/PFI projects include BuiltOperate-Transfer (BOT), Build-Lease-Transfer (BLT), Build-Operate-Own (BOO), Build-Lease-MaintainTransfer (BLMT), land swap, contract management, and corporatization. Table 1 shows the PPP method implementation in Malaysia. According to Takim et al. [37] and Shamsida and Ani Saifuza [26], the organizational structure of a typical PPP in Malaysia does not differ much from international best practice. The composition comprises the government, the Special Purpose Vehicle (SPV), lenders, private investors, works contractors, and facilities maintenance contractors. The roles of the parties in Malaysian PPP/PFI resemble their partners around the world.

Ahadzi and Bowles [36] state that, the whole PPP procurement mechanism may be segregated into four stages, i.e., planning and feasibility study phase, bidding, and negotiation phase, construction phase, and operation phase, with the possible addition of relocation and renegotiation phase. According to Wang and Dai [41], there are five various types of methodologies that can be used in PPP tenders; open competitive tendering, invited tendering, registered lists, project specified prequalification and shortlisting, and negotiated tendering.

Table 1. PPP Method (3PU/UKAS, 2010)

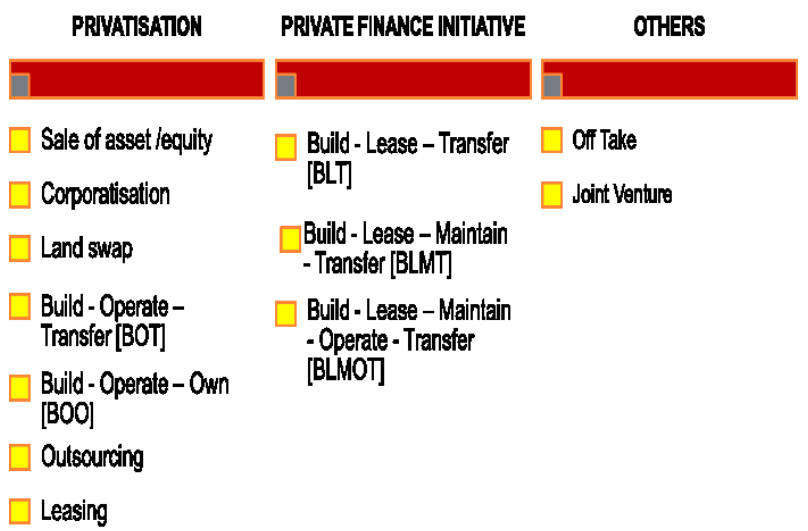

The most common procedure is the open competitive tendering, which involves the phases of a request for prequalification, prequalification, invitation to tenders, tender evaluation and shortlisting, negotiation with shortlisted tenders/bidders and selection of best bidding and award. Even though calling for bidders to be prequalified and calling for tenders of qualified bidders were simple tasks, Tiong and Alum [42] stated that there 
are three main phases that can be distinguished in the tendering procedure of PPP, which are prequalification of tenders, evaluation tenders, negotiation with preferred bidders, before PPP awarding. Figure 1 shows the "End to End" process under the Malaysia PPP/PFI procurement process.

According to Zawawi et al. [43], the Government of Malaysia assigned Unit Kerjasama Awam Swasta (UKAS) as the central agency to facilitate and coordinate PPP/PFI procurement in the country. UKAS was established as an initiative and a continuous commitment by the Government to assist and ensure the success of the national PPP programmed. It is the core agency responsible for coordinating and supervising the national PPP implementation [29]. Ministries or agencies prepared PPP project proposals and submitted to UKAS for consideration and approval of the Cabinet Ministers [29]. UKAS has evolved from a small task force to monitor the implementation of privatization to a more prominent role and additional authority. The task force upgraded into a new government agency under the prerogative of the Prime Minister's Department. If the yardstick of success is measured by delivering infrastructure to the people, the credit is due to the agency for its achievements.

A survey by Zawawi [43] and Saidan Khaderi and Abdul Aziz [24] identified that there are neither new legal frameworks nor specific legislation for PPP in Malaysia. UKAS operates using the organization's guideline, the Privatization of Masterplan, and other significant national policies. UKAS published the Guideline on Public-Private Partnership in 2009. The intention was to produce clear instructions on the principles adopted, criteria for project development, justification, and selection criteria for projects [29].However, the guidelines are very general and do not have an established mechanism for dealing with the unsolicited [24]

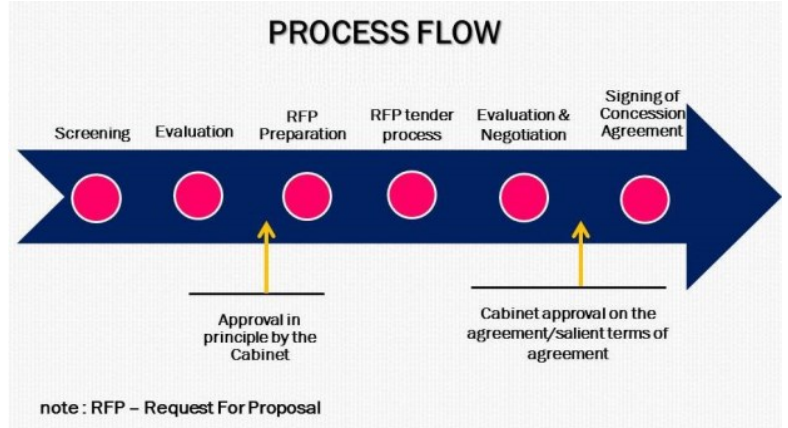

Fig. 1. "End to End" Process (3PU/UKAS, 2010)

Let's begin with the initial phase in the tendering procedure of PPP, i.e., the stage of prequalification of tenders. The objective of this phase is to avoid the avoidable tendering cost from weak bidders. Only the prominent and experienced bidders can carry out the project risk. Thus, the number of interested tenders will be reduced to be a shortlist. The next phase is the evaluation tenders. At this stage, one or more among the qualified bidders will be selected. They are shortlisted and persuade to submit a structured proposal that will be evaluated by the predefined evaluation criteria. After that would be the negotiation with preferred bidders' phase. This phase consists of negotiation before final awarding with one or a few preferred bidders. At this time, the provisions in the agreement are thoroughly reviewed. Once signed, the contract decision will be issued to the winning bidder, and the contract is taking effect. Figure 2 shows the Process Flow of PPP/PFI projects in Malaysia. According to and Ozawa [27], the prequalification phase is missing in some Asian countries like Hong Kong, Thailand, and Malaysia because the governments think that, due to the tremendous effort required by such work, only big experienced companies could take part to tender.
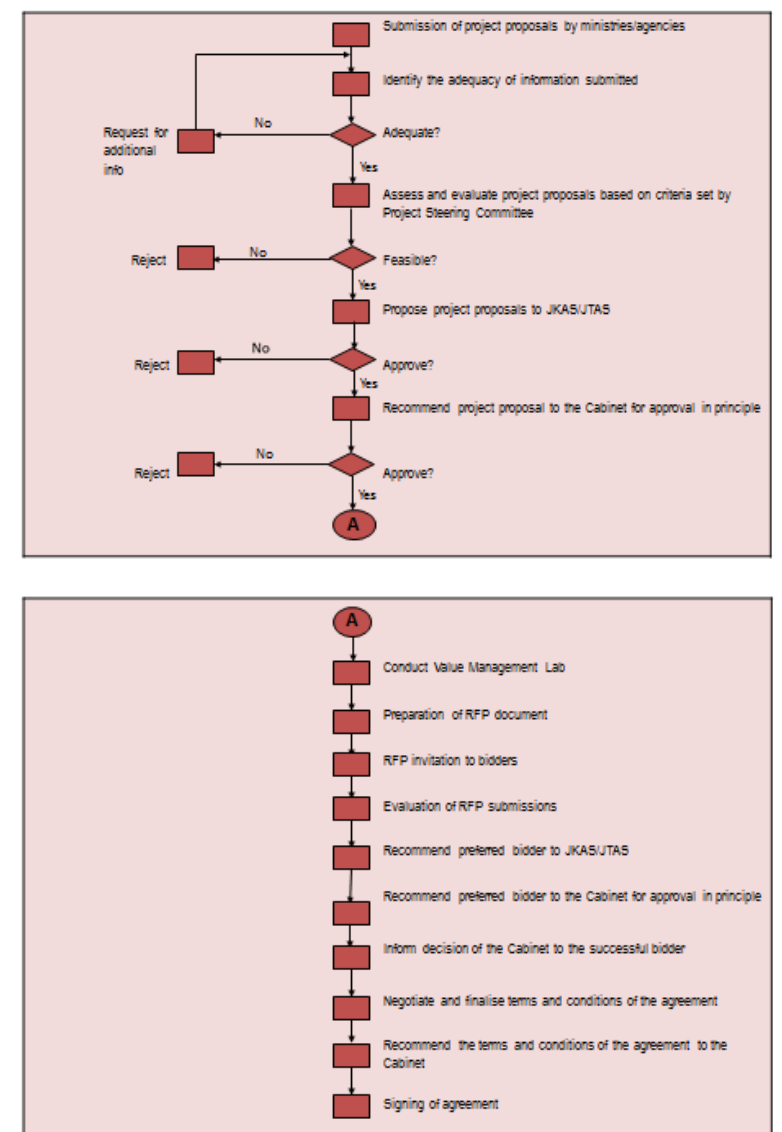

Fig. 2. Process Flow of PPP/PFI Projects (3PU/UKAS, 2010)

According to Saussier et al. [25], Public-Private Agreement (where PPP is considered as an example), a final negotiation phase after the tender evaluation is useful because it allows joining the flexibility needed in such a rigorous and challenging project given the tendering mechanism. Doni [12] looked at three kinds of tendering procedures, which are the negotiation, the auction, and the competitive negotiation procedure to provide contracting authorities with guidelines to follow for designing PPP/PFI tenders. In the absence of consent between one bidder and the public sector, the competitive negotiation will give a higher expected value to the government compared to other methods. In 
different situations, competitive tendering can work much better than negotiation only if the supplier's market is widely competitive. Figure 3 shows the overview process of tendering in the UK's PFI procurement process. All stages of the agreement must be managed effectively including the tendering stage.

According to ADB et al. [1], most of the characteristics of the tender process will be the same as in any public procurement process, but some stages and steps have specific aspects and features. Special considerations inherent to the complexities of PPPs are as the following:

- Time to prepare and submit offers: This will usually be longer than in a conventional procurement. Due to the intricacies of the PPP processes (including complexities faced by the private partner), it is essential to grant the bidders enough time for proper due diligence, analysis, and assessment of the project and the contract from different fronts.

- Interaction with the market/bidders: As explained before, an initial interaction/communication process should be carried out before the tender launch occurs. However, some interaction should also take place during the tender process to better inform the bidders about the project and to clarify potential inconsistencies or to amend unintended errors in the wording of the request for proposal (RFP) and the contract. In some countries, more extensive interaction occurs. A balance is needed so as not to endanger the legality of the process and potentially suffer a challenge that may paralyze the process or require the government to re-issue the tender.

- Risks of problems to the process: Due to the incremental complexity of the contract and operation, the risk of a challenge is considered higher in PPPs than in a conventional procurement. In addition to the possibility of a problem by an unsuccessful bidder, in some countries, it may be possible under the administrative law for the broader public and civic organizations to challenge the process if their interests' conflict with the nature and objectives of the PPP. There may also be non-legal routes to test the process (for example, by applying political pressure). Some bidders may be willing to force a project cancellation because they may not be ready enough to participate (which links to the first concern expressed above about allowing enough time to bid). The risk may exacerbate in countries in which both the public and private sectors lack PPP experience. As such, there are no shared expectations as to how the process will unfold.

- Time for evaluation: Evaluating PPP bids is a more complicated matter than evaluating standard contracts. PPP evaluation requires a knowledge of both the PPP's technical and financial features, including the particularities of the technical proposal and how it interacts with the economic sustainability of the offer. The room for potential non-compliance with the proposal requirements is significantly larger than in a conventional procurement. Linked with the higher risk of challenges, it also needs to be accurate and stick with the rules and methodology for bid evaluation (and selection/qualification) as described in the RFP.

- Contract signature or management of the contract signature process is more demanding for both the public and private parties. An extended period is required to allow the private partner to prepare for signature, especially (in some jurisdictions) the need to form an SPV that will sign the contract.

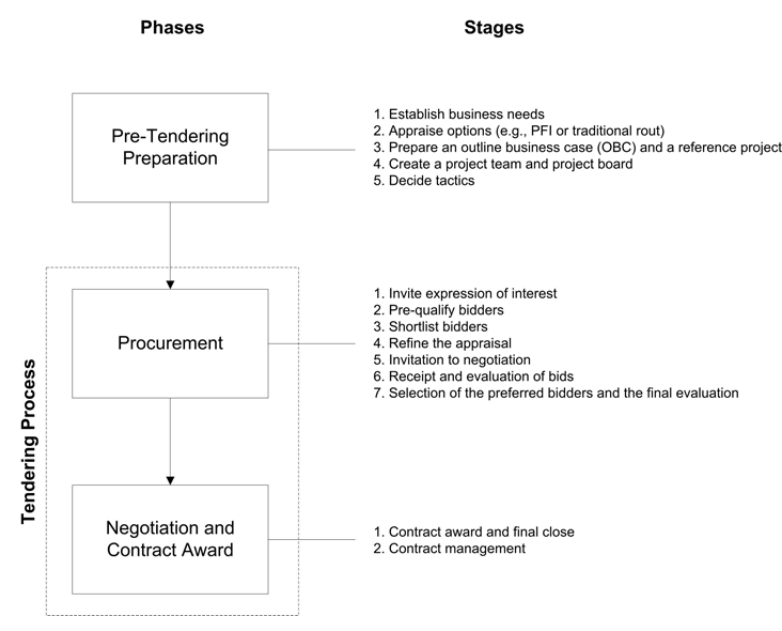

Fig. 3. UK's PFI Procurement Process [44]

It is essential that the bidding process is transparent, clearly spelled out where the short-listed company is invited for negotiation to get the project. But in Malaysia, the open tender is not fully applied, and there are several companies which have already been awarded projects under the PPP procurement without any competitive bidding [24]. It is crucial that open competitive tender process is adapted to select the most qualified contractor based on their expertise and experience.

It can conclude that tendering phase is one of the most critical aspects in PPP/PFI, but there are lacks intention focusing on this instead of the implementation and so on. Different countries are adopting a different kind of tendering procedure. Thus, it would be useful to understand what kind of methods of PPP/PFI tender might differ from one to another country that implementing it, for example in the UK the standard procedures are open competitive tendering while in Malaysia, our PPP/PFI projects mostly are using invited tendering. Next, methods used in awarding the private also can be vary due to the complexity of the PPP/PFI projects. Thus, contractors must have an effective plan and mechanism in place to produce a winning bid for a PFI contract. 


\section{Issues and Challenges in PPP Tendering Process}

Tendering process is critical for the public client in $\mathrm{PPP} / \mathrm{PFI}$ venture procurement to gain value for money. It relies upon the existence of a competitive bidding process. The guideline of the significance of value for money and whole life costing would require the government to emphasize the best value, and not necessarily the lowest initial price. In this way, the bidders must guarantee that their costs are the lowest for the whole life of the concession, not just at the initial of construction. There is an issue where the contractors often said that high bid costs prevent them from bidding for more PFI projects. There is a healthy number of contractors in PPP/PFI market, but the number of bidders for each project is falling according to Great Britain Parliament: House of Commons [32].

The Construction Industry Council [31]bai stressed that the bidding for PFI projects is intrinsically complicated and initially expensive. Once the bidder has the experience, the following bids should be cheaper. The PFI projects had been awarded through competitive bidding. It is a necessity to process in extracting value for money from the PFI. It is significant for both public and private sector partners to recognize the importance of an effective procurement competition as bidding costs for PFI projects. PFI/PPP explicitly designed for largescale, high-value projects such as road/rail infrastructure networks or hospitals. It is a result of the shift toward privatization. A construction company looking for a long-term involvement needs to formulate a strategy to deliberate over the type of PFI projects to be focused on.

$\mathrm{PPP} / \mathrm{PFI}$ tendering procedure is more complicated and costlier compared to traditional process [7]. As an example, in UK's PFI project tender costs, Design and Build and traditional method reveal high total project cost as compared to PPP/PFI (higher range between $0.48 \%$ to $0.62 \%$ ). The surveys by Akintoye and Dick showed that the bidding cost is a significant problem in PFI. This review was additionally upheld by the Contract Journal and Knowles survey in the same year showing that the respondents rated the price and the bidding process in the scale of 8 from 10 for PFI as being unattractive. Dixon et al. [11] stated that the high bidding costs represent an opportunity cost and high risk to firms contemplating market entry, act as barriers of participation in the PFI market and reduce market competitiveness. Akintoye et al. expect that the bid cost for a PFI project could be as much as $£ 0.5 \mathrm{~m}$, contingent upon the project size with even the biggest contractors discouraged. Due to tendering cost risk, most of the contractors have refused to become engaged with PPP/PFI work.

The lengthy procurement period and a high-cost impact on the negotiation of PPP/PFI deals. The average procurement time for $\mathrm{PPP} / \mathrm{PFI}$ ventures is around 22 months in UK and 12 to 18 months in Australia. It required a long time to come up with an acceptable risk transfer, payments and other terms on both sectors side. In some cases, the significant causes of delay were either avoidable or could have been mitigated by the public sector without compromising the value for money such as insufficient specifications before marketed, changes to the scope and design of projects, and poor management process [19] The risk of procurement time and cost overruns has been a component of most of the PFI projects, for example, in the case of the road project in Scotland. Because of a broad meeting with the bidders, the procurement timescale had to be revised from 17 to 27 months. Ahadzi and Bowles [3] cited that the National Audit Office demonstrated that due to this and other unforeseen events, the procurement cost to the public-sector procurer had increased from $£ 1.3 \mathrm{~m}$ to $£ 2.85 \mathrm{~m}$.

According to Yong [18], it is challenging towards estimating facility management costs in a long-term concession in Malaysia. The technique for tendering or negotiation should be straightforward, with three critical conditions noted by The National Audit Office [21] and Li et al. [20], i.e., a good tender list of firms invited to bid, an explicit specification in requirements, and competitive tension maintained throughout the procurement process. To be a straightforward process, it requires an effective communication that is open as far as possible to a public inquiry.

According to APMG et al. [1], the risk of a challenge to the tender or award process is considered higher in PPPs than in a conventional procurement. The procuring authority must have sound preparation and procurement processes, and a legal team and relevant subject matter experts prepared to handle potential challenges including the ability to resolve disputes in the interests of moving the process forward. Problems may come after soft launch, or after award of the contract.

\section{Strategies to Enhance PPP Tendering Process}

Many authors have proposed an alternate arrangement of policy to enhance PPP tendering process. All phases of a project need to be overseen well, including the tendering stage. Many authors put forward several bidding proposals to strengthen public sector skills and procurement support and to reduce procurement timescales and costs for both the public and private sectors. These incorporated a more prominent accentuation on the readiness of projects before they go to the market, increased monitoring and scrutiny of projects, including a new stage of investigation before selection of the preferred bidder.

PPP procurement development takes longtime than numerous traditional types of procurement imported into the construction industry previously. To reduce the 
bidding cost which will not affect the value for money of the PPP/PFI project, there are few strategies recommended for the government[22] had classified these strategies as to avoid a premature projects announcement and allowing enough time for pre-tender phase arrangement. It needs a proper study on the market of PPP before any plan of project issued. Next, release the demand for a structured proposal once all the necessary preliminary works have been completed, so that it can lower the need for addendum and re-bids. Then, another strategy to be adopted is reducing the amount of bid phase design work required from the bidders rather than placing greater dependence on the project prerequisites.

The government should also assure more financial institutions to participate in PPP/PFI to facilitate the issue of adequate finance facilities faced by the concessionaires. It may divert the skepticism in providing financial support for PFI projects. An education programmed on the mechanism of PPP/PFI should be held to all parties to make it more attractive. After so much constraints derived respecting PPP/PFI matters, the best way forward is to improve the PPP/PFI procurement commonly and tendering procedure undoubtedly in the future. According to Reeves et al., the history of PPP procurement in the UK recommends that the endeavors to enhance the execution of the tendering process have been ongoing since the early days of the PFI. The official report of the PFI has, over time, emphasized the objective of strengthening the procurement procedure.

\section{Conclusion}

The process of public infrastructure tendering trough PPP required a complete systematic approach as compared to traditional procurement method. Thus, to understand the PPP bidding process, this paper has discussed the review of the literature. It has highlighted the various PPP tendering procedure, issues and challenges together with strategies to enhance PPP bidding process. A project taking the PPP/PFI route is often more complicated in building technologies and specification. Subsequently, it requires a more complicated form of procurement, outstanding a much longer negotiation time before the works commence. Based on the literature review on the type of the method commonly applied in the UK, the Malaysian system holds a different procedure in implementing the process. Most of the models in the Malaysian PPP/PFI tender are using invited tendering compared to the UK, which used open competitive tendering.

To attract more cooperation from the private sector in PPP/PFI ventures, it is recommended for the procuring authorities to be given enough allocation of time and resources to develop and prepare their plans before formal engagement is being made. From the literature review, it is essential to create and enforce standardized contractual guidance in providing a better understanding of both the private and public sectors. Furthermore, a standard guideline is necessary to guide the path in ensuring all method are manage clearly so that the products and services afford to represent a good value for money.

The authors would like to thank University Technology MARA (UiTM) for providing the opportunity to participate in this conference (Reference :600-IRMI/Dana KCM 5/3/LESTARI (114/2017). Special thanks also go to the reviewers for the invaluable comments on this paper.

\section{References}

1. ADB, EBRD, IDB, IsDB,MIF, PPIAF and WBG, The APMG PPP Certification Guide - Request for proposal.[Online] Available; $\underline{\text { https://ppp- }}$ certification.com/ppp-certification-guide/3-specialcharacteristic-ppp-tender-process [Accessed 2016]

2. E. Anders, P. Schutze, Organizing and Financing of Public Infrastructure Projects. A path to Economic Growth and Development of the Danish Welfare Model- Main Report. Public Private Partnerships Copenhagen [Accessed May 15,2013]

3. M. Ahadzi, G. Bowles, The Private Finance Initiative: The Procurement Process in Perspective". Proceedings of the 17th Annual Conference of ARCOM, Salford, 2001 pp. 971-980

4. A. Akintoye, M. Beck and C. Hardcastle, Public Private Partnerships - Managing Risks and Opportunities. Blackwell Publishing ,2003

5. A. Akintoye, C. Hardcastle,, M. Beck, E. Chinyio, and D. Asenova, Achieving best value in private finance initiative project procurement'. Construction Management and Economics, Vol. 21, pp. 461-470 ,2003.

6. $\mathrm{K}$. Beeston, Is the price is right? PFI Journal. [Online].Available: www.cbi.org.uk [Accessed January 20,(2007)

7. J. Birnie, Risk Allocation to the Construction Firm within a Private Finance Initiative (PFI) Project. ARCOM Conference Proceedings,1997.pp. 527-534

8. N. Carbonara, L. Gunnigan, R.and F. Sciancalepore, Tendering Procedures in PPP: A literature review. School of Surveying and Construction Managament, Dublin Institute of Technology ARROW@DIT,2012.

9. Deloitte, Government and public sector- building flexibility-New delivery models for public infrastructure projects ,2006

10. I. Demirag, M. Dubnick, and M. Khadaroo, $A$ framework for examining accountability and value for money in the UKs private finance initiative. Greenleaf Publishing. Autumn ,2004.

11. T. Dixon, G. Pottinger and Jordon, A lesson from the private finance initiative in the UK: Benefit, problems and critical success factor. Journal of property investment and finance, 23(5), pp. 412-423 ,2015.

12. N. Doni, A Comparison of Alternative Procedures for the Selection of the Private Partner in PPP 
Projects. Working Paper Università degli Studi di Firenze., 2007.

13. Economic Planning Unit, Ninth Malaysia Plan 2006-2010. EPU, Malaysia. ,Feb 15 2007, [Online]. Available : http://www.epu.jpm.my/rm9/english/chapter10/pdf [Accessed 2006]

14. I. R. Endut, Framework for minimizing time overruns of Malaysia construction projects. A Ph.D. Thesis, Glasgow Caledonian University,2008.

15. E. E.Endicott, PFI: A step in the right direction. PFI Journal. ,2001 [Online] Available :15 January 2007, www.frost.com from the World Wide Web[Accessed ,2001]

16. C. Hardcastle, The private finance initiative - friend or foe. Glasgow Caledonian University, Scotland UK ,2006.

17. HM Treasury,. PFI: Meeting the investment challenge. HMSO London, 2003 [Online]

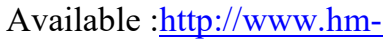
treasury.gov.uk/media/648B2/PFI_604.pdf [Accessed February 14,2007]

18. H. K. Yong, Public-Private Partnerships Policy and Practice. A reference guide.Commonwealth Secretariat, ISBN :978-84929-020-3,2010.

19. HM Treasury, PFI: Strengthening long-term partnerships. HMSO, London,2006 [Online] Abvailable. $\quad$ http://www.hmtreaury.gov.uk/media/IEI/33/bud06_pfi_618.pdf [Accessed December 10,2006]

20. B. Li, A. Akintoye, P. P. Edwards and C. Hardcastle, Critical success factors for PPP/PFI Projects in the UK construction industry. Construction Mgt. \& Economic. June 23,2005,pp.459-471

21. NAO, Improving the PFI tendering process. Report by the Controller and Auditor General. HC 149 Seesion 2006-2007,2006.

22. S. Nurfarhana, Tendering Strategies in Winning PFI Contract. Unpublished Degree Thesis. University Teknologi MARA, Shah Alam, 2015.

23. S. Saidan Khaderi, Private Finance Initiative (PFI) Implementation in pre-construction stage. Unpublished Ph.D. Thesis. University Sains Malaysia ,2011.

24. S. Saidan Khaderi and A. R. Abdul Aziz A R, Adoption of PFI in Malaysian public works projects: Are we ready? CIB World Congress 2010, Salford University UK, 2010.

25. S. Saussier, C. Staropoli, A. Yvrande-Billon, Public-Private Agreements, Institutions, and Competition:When Economic Theory Meets Facts, Review of Industrial Organization, Vol.35, pp. 1$18,2009$.

26. S. K. Shamsida and A. S. Ani Saifuza, Innovative Implementation of PFI Procurement Challenges and Key Issues in Pre-Construction Stage. 7th Asian Conference on Environment Behaviour Studies, National Taiwan University Taipei, Taiwan. 9-10 April 2016.
27. R. L. K. Tiong, J. Alum, Evaluation of proposal for BOT projects, International Journal of Project Management, Vol. 15, No. 2, pp. 67-72,1997.

28. N. T. To, K. Ozawa, Evaluation of procurement system for BOT infrastructure in Asian Countries. Proceedings of the International Symposium on Social Management, , Hubai China 9-11 March, Hubai China, 2007.

29. UKAS (Unit Kerjasama Awam Swasta)/3PU PPP Guidelines, 2009 [Online] Available : http://www.ukas.gov.my/en/garis-panduan-ppp

30. UKAS (Unit Kerjasama Awam Swasta)/3PU, End to End Process - PPP Guidelines., 2010 [Online] Available : http://www.ukas.gov.my/en/end-toeprocessPPP Guidelines.

31. Construction Industry Council. Contractors' Key Guide to PFI, 1998.

32. Great Britain Parliament: House of Commons. Private Finance Initiative (PFI). Seventeenth Report of Session 2010-12 Vol. 1, 2010.

33. NAO. Private Finance Initiative - Construction Performances. National Audit Office, 2003.

34. I. Syuhaida \& M.D. Aminah. The provision of infrastructure via PFI - Theoritical and Empirical. Research in Urban Management. Special Number 15/April, 2009.

35. A. Merna \& M. Owen. The Private Finance Initiative. Centre for research into the Management of Projects, UMIST, 1999.

36. M. Ahadzi and G. Bowles. The PFI: The new procurement process in perspective. ArCoM Proceedings, 2004.

37. R. Takim, I. Kharizam and R. Abdul Rahman. The acceptability of PFI Scheme in Malaysia. Asian Social Science. Vol. 4 (12), pp 71-82, 2009.

38. The Edge. Untested model for Malaysian companies, The Edge Malaysia, pp 75, 2006.

39. I. Abdul Rahman, H.M. Aftab and M.Z. Nora Sheda. Public private Partnerships procurement methods in Malaysia construction industry. Journal of American Science, 10(7) : pp 91-97, 2014.

40. J. Broadbent and R.C. Laughlin. Public Private Partnerships introduction. Accounting Auditing \& Accountibility Journal, 16(3) :pp332-341, August, 2003.

41. D. Wang and D. Dai. Research on concessionnaire selection for BOT projects. Proceeding of International Conference on Management \& Service Science (MASS), Wuhan (China), 24-26 August, 2010.

42. R.L.K. Tiong and J. Alum. Evaluation of proposal for BOT Projects. International Journal of Project Management Vol. 15, No. 3, pp 67-72, 1997.

43. N.A.W.A. Zawawi, M. Ahmad, A.A. Umar, M.F. Khamidi \& A. Idrus. Financing PF2 Projects: Opportunities for Islamic Project Finance. Procedia Engineering77, pp 179-187, 2014.

44. Y.H. Kwak, Y.Y. Chih \& C.W. Ibbs. Towards a Comprehensive Understanding of PPP for Infrastructure Development. California Development Review, 51(2), pp52-78, 2009. 